\title{
Reversal by phenytoin of carbamazepine-induced water intoxication: a pharmacokinetic interaction
}

\author{
E PERUCCA AND A RICHENS
} From the Clinical Pharmacology Unit, University Department of Clinical Neurology, The National Hospital'
London

SUMMARY The hypothesis that phenytoin may antagonise the antidiuretic effect of carbamazepine has been examined by comparing the free water clearance response to a standard water load in 36 patients stabilised on different drug regimes. The diuretic response to the water load was significantly greater in patients receiving chronic treatment with carbamazepine and phenytoin in combination than in matched control subjects receiving carbamazepine as a single drug. Acute administration of phenytoin $(1,100 \mathrm{mg})$, however, had no significant influence on carbamazepineinduced antidiuresis. Evidence is presented that reversal of the antidiuretic effect of carbamazepine by chronic phenytoin administration is secondary to a marked reduction of the serum carbamazepine concentration during combined therapy. These results suggest that the risk of developing water intoxication is greater in patients receiving carbamazepine alone than in those receiving phenytoin in combination. Since the antidiuretic effect is correlated with the serum carbamazepine concentration rather than with the prescribed daily dose, monitoring the serum level of the drug is likely to provide the best rational approach to the prevention of excessive water retention.

Carbamazepine has antidiuretic properties which have been shown to be positively correlated with the concentration of the drug in serum..$^{12}$ Excessive water retention is relatively common at serum concentration values close to the upper limit of the therapeutic range (12 to $42 \mu \mathrm{mol} / \mathrm{l})$ and may be troublesome in some patients, particularly those receiving the drug for the treatment of epilepsy and trigeminal neuralgia. ${ }^{1-5}$ Interestingly, water intoxication appears to be more common in patients treated with carbamazepine alone than in those receiving phenytoin in combination $^{2}$ and reversal of carbamazepineinduced antidiuresis by phenytoin has been recently described in one patient. ${ }^{6}$ Although in the latter report the mechanism of the interaction was assumed to be pharmacodynamic, that is, related to the inhibitory action of phenytoin on the release of antidiuretic hormone (ADH) from the posterior pituitary, ${ }^{78}$ there are no experimental data to support this hypothesis. We now report the results of a study in which this interaction and the mechanisms involved have

Address for reprint requests: Dr A Richens, University Department of Clinical Neurology, The National Hospital, Queen Square, London WC1N 3BG.

Accepted 15 November 1979 been investigated in patients treated with carbamazepine, alone or in combination with phenytoin.

\section{Patients and methods}

Thirty-six epileptic patients of either sex, aged 20 to 57 years, and eleven drug-free normal control subjects were studied. Most patients were resident at the Chalfont Centre for Epilepsy, with the exception of five patients who attended the Outpatients' Department of the National Hospital, Queen Square. All were stabilised on chronic treatment with carbamazepine alone or in combination with phenytoin; patients on other drugs were excluded from the study. All subjects had a normal plasma sodium and osmolality prior to the study. Subjects were assigned to different groups according to drug treatment (table). Age, sex and weight distribution were similar for each group. The antidiuretic effect of carbamazepine was assessed quantitatively by measuring the free water clearance in response to a standard water load $(20 \mathrm{ml} / \mathrm{Kg}$ up to a maximum of $1600 \mathrm{ml})$ in each subject. Details of the experimental procedure have been described elsewhere. ${ }^{2}$ Serum and urine osmolality were determined by means 
Table Carbamazepine (CBZ) dose, serum phenytoin $(D P H)$ and carbamazepine concentration and diuretic response to a standard water load (mean \pm s.d.) in the subjects included in the study

\begin{tabular}{|c|c|c|c|c|c|c|c|c|c|c|}
\hline Group & $n$ & Treatment & Comment & $\begin{array}{l}\text { CBZ dose } \\
(m g / \text { day })\end{array}$ & $\begin{array}{l}\text { Serum } C B Z \\
\text { concentration } \\
(\mu \mathrm{mol} / \mathrm{l})\end{array}$ & $\begin{array}{l}\text { Serum DPH } \\
\text { concentration } \\
(\mu \mathrm{mol} / \mathrm{l})\end{array}$ & $\begin{array}{l}\text { Per cent of } \\
\text { water } \\
\text { excreted }\end{array}$ & $\begin{array}{l}\text { Peak free } \\
\text { water } \\
\text { clearance } \\
(\mathrm{ml} / \mathrm{min})\end{array}$ & $\begin{array}{l}\text { Minimal } \\
\text { urine } \\
\text { osmolality } \\
(\mathrm{mOsm} / \mathrm{Kg})\end{array}$ & $\begin{array}{l}\text { Number of } \\
\text { subjects with } \\
\text { abnormal } \\
\text { response }\end{array}$ \\
\hline 1 & 11 & - & Controls & - & - & - & $89 \pm 12$ & $9 \cdot 4 \pm 3 \cdot 4$ & $69 \pm 20$ & 0 \\
\hline 2 & 6 & $\mathrm{CBZ}$ & $\begin{array}{l}\text { Patients } \\
\text { matched for }\end{array}$ & $1300 \pm 330$ & $39 \pm 5$ & - & $34 \pm 22^{*}$ & $1 \cdot 6 \pm 2 \cdot 6^{*}$ & $358 \pm 274^{*}$ & 5 \\
\hline 3 & 6 & $\mathrm{CBZ}+\mathrm{DPH}$ & CBZ dose & $1300 \pm 330$ & $25 \pm 4 \dagger$ & $47 \pm 13$ & $68 \pm 29 \dagger$ & $4 \cdot 7 \pm 3 \cdot 9$ & $97 \pm 46 \dagger$ & 1 \\
\hline 4 & 6 & CBZ & $\begin{array}{l}\text { Patients } \\
\text { matched for } \\
\text { serum CBZ }\end{array}$ & $815 \pm 430$ & $33 \pm 4$ & - & $41 \pm 22^{*}$ & $2 \cdot 5 \pm 4 \cdot 3^{*}$ & $240 \pm 247$ & 4 \\
\hline 5 & 6 & $\mathrm{CBZ}+\mathrm{DPH}$ & concentration & $1500 \pm 310 \dagger$ & $33 \pm 4$ & $46 \pm 17$ & $33 \pm 26^{*}$ & $1 \cdot 9 \pm 4 \cdot 1^{*}$ & $289 \pm 175^{*}$ & 5 \\
\hline $\begin{array}{l}6 \mathrm{~A} \\
6 \mathrm{~B}\end{array}$ & $\begin{array}{l}7 \\
7\end{array}$ & $\begin{array}{l}\mathrm{CBZ} \\
\mathrm{CBZ}+\mathrm{DPH}\end{array}$ & $\begin{array}{l}\text { Acute within } \\
\text { subjects study }\end{array}$ & $\begin{array}{l}1200 \pm 365 \\
1200 \pm 365\end{array}$ & $\begin{array}{l}38 \pm 4 \\
32 \pm 7 \dagger\end{array}$ & $\overline{34} \pm 13$ & $\begin{array}{l}33 \pm 18^{*} \\
41 \pm 25^{*}\end{array}$ & $\begin{array}{l}1 \cdot 0 \pm 2 \cdot 7^{*} \\
1 \cdot 3 \pm 2 \cdot 7^{*}\end{array}$ & $\begin{array}{l}342 \pm 255^{*} \\
307 \pm 260^{*}\end{array}$ & $\begin{array}{l}6 \\
5\end{array}$ \\
\hline
\end{tabular}

* $p<0.05$ or better (difference from controls).

$\dagger \mathrm{p}<0.05$ or better (difference between paired groups).

of an Advanced DigiMatic Osmometer, Model 3DII (Advanced Instruments Inc., Needham Heights, MA). The serum concentration of carbamazepine and phenytoin was detcrmined by enzyme-immuno assay (EMIT) in samples collected immediately before and after the water load test (the concentrations reported represent the mean of these two values).

\section{Results}

\section{Effect of phenytoin in patients matched for carbamazepine dose}

The effect of chronic administration of phenytoin on carbamazepine-induced antidiuresis was examined by comparing the free water clearance response to a standard water load in six patients stabilised on carbamazepine alone (dose range 800 to $1800 \mathrm{mg} /$ day) and in six matched subjects receiving chronic treatment with identical carbamazepine doses in combination with phenytoin. As illustrated in fig $1 \mathrm{~B}$, the diuretic response was found to be markedly impaired in patients treated with carbamazepine alone but the same was not true in the case of patients receiving phenytoin in combination. In the latter group, the fraction of the water load excreted during the test was found to be twice as high as in patients treated with carbamazepine alone $(p<0.05)$ and, although lower, did not differ significantly from that observed in drug-free normal control subjects (table). In particular, only one of the phenytointreated patients had an abnormal diuretic response (defined as a urinary output below $60 \%$. of intake), while five out of the six patients included on the monotherapy group had abnormal responses. When steady state serum carbamazepine levels in the two groups was compared, however, a marked difference was found, patients on combination therapy showing significantly lower levels that patients treated with carbamazepine alone.

It is evident from fig 2 that the reduction in the antidiuretic effect of carbamazepine in the presence of phenytoin was associated with
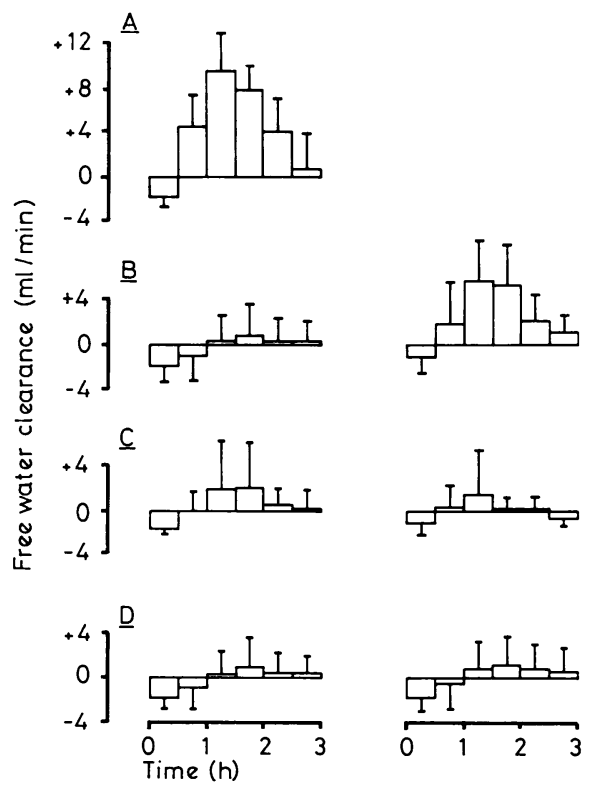

Fig 1 Free water clearance response (mean \pm s.d.) to a standard water load in normal control subjects ant in patients treated with carbamazepine alone (left) or in combination with phenytoin (right). $A=$ normal subjects $(n=11) ; B=$ patients matched for carbamazepine dose $(n=12)$; $C=$ patients matched for serum carbamazepine concentration $(n=12) ; D=$ patients given acute phenytoin loading $(n=7)$. See text for details. 

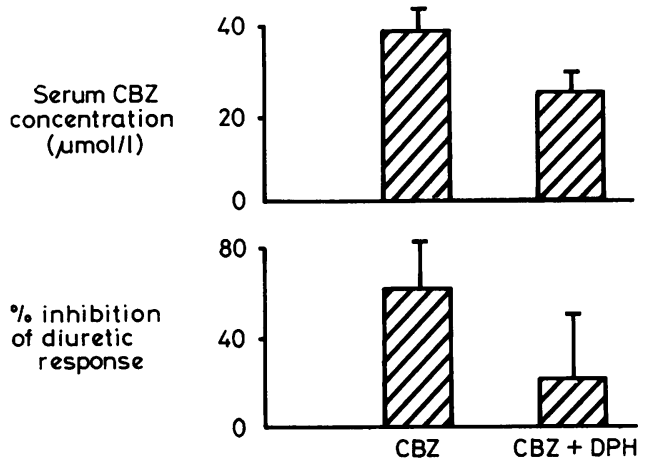

Fig 2 Serum carbamazepine concentration and antidiuretic effect (expressed as per cent inhibition of control diuretic response) in 12 epileptic patients treated with carbamazepine alone $(C B Z)$ and in combination with phenytoin $(C B Z+D P H)$. Patients were matched for carbamazepine dose.

markedly lower serum carbamazepine levels in patients receiving combination therapy.

\section{Effect of phenytoin in patients matched for serum carbamazepine concentration}

In order to ascertain whether the increased diuretic response in phenytoin-treated patients could be entirely accounted for by the lower serum carbamazepine levels in this group, water load tests were performed in six patients on carbamazepine alone and in six matched control subjects showing equivalent serum carbamazepine concentration but receiving phenytoin in combination. The diuretic response was found to be impaired to a similar extent in both groups (fig 1C and table). The dose of carbamazepine required to produce equivalent serum carbamazepine levels was significantly higher in patients receiving phenytoin, compared with patients treated with carbamazepine alone. As these findings further suggested that the inhibition of the antidiuretic effect of carbamazepine by phenytoin was secondary to a decrease of serum carbamazepine levels during phenytoin therapy, a withinsubjects study was undertaken in which the effect of acut phenytoin administration was examined in patients receiving chronic treatment with carbamazepine alone. This would not be expected to lower carbamazepine levels to any appreciable extent.

Effect of acute phenytoin administration

Seven patients stabilised on carbamazepine alone (dose range 800 to $1800 \mathrm{mg} /$ day) were included in this study. The diuretic response to a standard water load was determined in each patient on two different occasions separated by one week: 1 ) dur- ing regular treatment with carbamazepine alone and 2) following acute administration of phenytoin $(1100 \mathrm{mg}$ orally given in three doses of $500 \mathrm{mg}, 400 \mathrm{mg}$ and $200 \mathrm{mg}$ at 24,12 and $0.5 \mathrm{hrs}$ prior to water loading respectively). The carbamazepine dose was maintained unchanged throughout the study and the sequence of testing was randomised.

As illustrated in fig $1 \mathrm{D}$ and the table, the excretion of water was markedly impaired in six patients. Acute administration of phenytoin had no significant influence on the diuretic response, which was only marginally greater than in the presence of carbamazepine alone. In six out of seven patients, the serum carbamazepine concentration fell slightly but significantly $(p<0.05)$ after acute phenytoin administration, as compared to the values found during treatment with carbamazepine alone. In only one patient did the diuretic response reverse from abnormal ( $24 \%$ of water load excreted) to normal $(70 \%)$ in the presence of phenytoin: the effect, however, was accompanied by a reduction in the serum carbamazepine concentration from $36 \mu \mathrm{mol} / 1$ to $28 \mu \mathrm{mol} / 1$.

Relationship between dose, serum carbamazepine concentration and diuretic response

Observations on the relationship between serum carbamazepine levels, dose and fraction of the water load excreted were extended to include 36 patients. There was no significant relationship between the magnitude of the diuretic response and the prescribed daily carbamazepine dose expressed per unit of body weight $(r=-0 \cdot 23$, $\mathrm{p}>0.05$ ). However, when log-serum carbamazepine concentration values were plotted against diuretic response, a significant negative correlation was found $(r=-0 \cdot 44, p<0 \cdot 01)$. Impairment in the ability to excrete a water load was particularly common at serum carbamazepine levels above $28 \mu \mathrm{mol} / 1$. Although the correlation between diuretic response and serum carbamazepine concetration was stronger in patients treated with carbamazepine alone $(r=-0 \cdot 62$ vs $-0 \cdot 36)$. neither the slope nor the intercept of the regression line were significantly different in patients on a single drug, compared with patients receiving phenytoin in combination.

Serum carbamazepine concentration in patients treated with carbamazepine alone and in combination with phenytoin

The observation that patients receiving phenytoin in combination had lower serum carbamazepine levels than patients treated with carbamazepine 


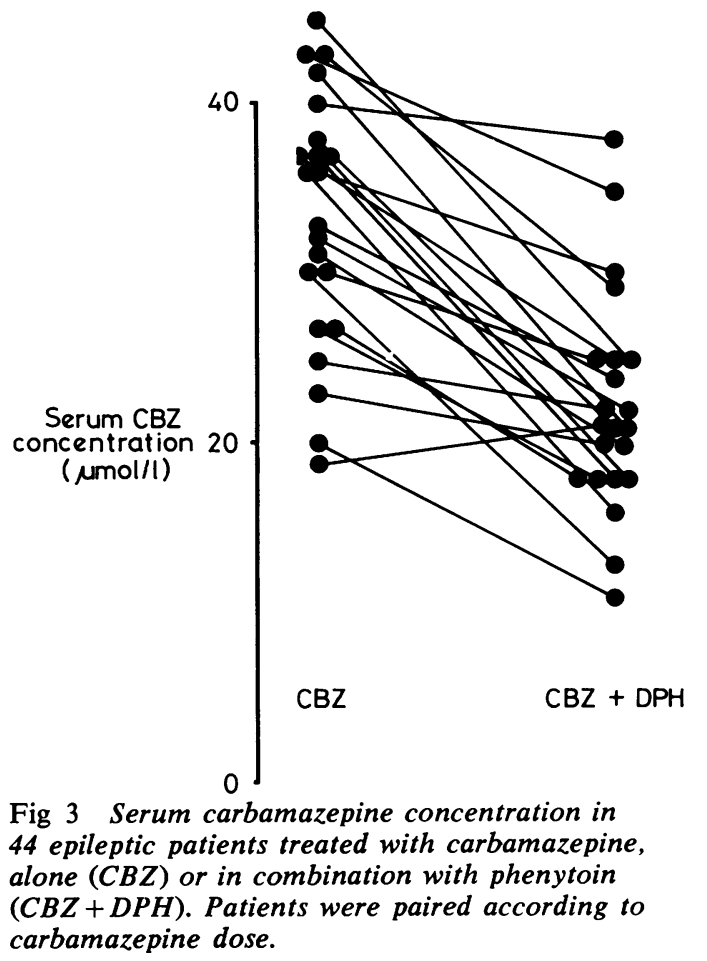

alone was extended to include a larger number of subjects. Twenty-two patients receiving single drug therapy were paired with a corresponding number of patients treated with identical doses of carbamazepine in combination with phenytoin. As illustrated in fig 3 , in 21 out of 22 pairs carbamazepine levels measured in fasting serum samples were higher when carbamazepine was used as single drug $(\mathrm{p}<0.01)$. In patients treated with carbamazepine alone, serum carbamazepine levels were on average $50 \%$ higher than in patients receiving combination therapy (mean ( $\pm \mathrm{SD}$ ) values $33 \pm 8$ vs $22 \pm 6 \mu \mathrm{mol} / \mathrm{l}$ respectively), in remarkably good agreement with the findings obtained by comparison of a smaller number of subjects.

\section{Discussion}

This study confirms that carbamazepine treatment may result in an impaired ability to excrete a water load and demonstrates a clear relationship between the magnitude of this effect and the concentration of carbamazepine in serum. A negative correlation between plasma sodium, osmolality and serum carbamazepine concentration has been described before in patients with epilepsy and trigeminal neuralgia. ${ }^{12}$
Our original hypothesis that phenytoin may antagonise the antidiuretic effect of carbamazepine was confirmed by the finding that the diuretic response in patients receiving phenytoin in combination was twice as high as in patients receiving equivalent doses of carbamazepine alone. Our data suggest that the difference could be entirely accounted for by a decrease in serum carbamazepine levels during phenytoin therapy. A lowering effect of phenytoin (and phenobarbitone) on serum carbamazepine levels has been described previously by Christiansen and Dam $^{9}$ in a comparative study of two different groups of patients, and by Cereghino et $a^{10}$ in a within-patient controlled trial. In both of these studies, the magnitude of the effect was remarkably similar to that observed by us. It is of interest that, in our own study, acute administration of phenytoin, $1100 \mathrm{mg}$ over a period of $24 \mathrm{hr}$, was sufficient to produce a small but significant decrease of the serum carbamazepine concentration in six out of seven subjects. Such an immediate effect appears to be more consistent with an interaction at the absorption site than with induction of carbamazepine metabolism by phenytoin, as generally assumed. ${ }^{11}$ On the other hand, induction of carbamazepine metabolism by phenytoin and phenobarbitone is strongly suggested by the shorter carbamazepine half-life and the increased ratio of carbamazepine-10, 11epoxide to parent drug in the serum of the same patients. ${ }^{12-15}$ Although the epoxide may share some of the pharmacological properties of the parent drug, its accumulation in serum during phenytoin therapy does not appear to compensate to a very important degree for the observed reduction in antidiuretic effect.

The suggestion that phenytoin might antagonise the antidiuretic action of carbamazepine through a pharmacodynamic interaction-for example by inhibiting ADH release from the pituitary-is not supported by our findings. Acute administration of phenytoin did not consistently reverse the antidiuretic effect of carbamazepine; the small increase in diuretic response in some patients following phenytoin intake could have been accounted for entirely by the slight fall in serum carbamazepine concentration which was seen in the same patients after acute phenytoin administration. Lack of pharmacodynamic interaction between carbamazepine and phenytoin is further suggested by the observation that in patients with equivalent serum carbamazepine levels, the diuretic response is impaired to a similar degree whether phenytoin was present or not. Moreover, phenytoin did not appear to influence the regres- 
sion line relating serum carbamazepine concentration to antidiuretic effect.

The lack of a pharmacodynamic interaction between phenytoin and carbamazepine may provide indirect evidence on the mechanism of action of the latter drug. Fichman, Bethune and Kleeman $^{16}$ have proposed that intravenous administration of phenytoin be used as a diagnostic test to distinguish the syndromes of inappropriate secretion of ADH of non-tumorous etiology (reversed by phenytoin) from those resulting from tumorous production of $\mathrm{ADH}$, or from increased renal responsiveness to the hormone. Our data suggest that carbamazepineinduced antidiuresis is mediated by the last mechanism, at least in patients with normal plasma sodium and osmolality. However, our evidence cannot be regarded as conclusive because phenytoin was given orally and it has been questioned whether the drug is effective in inhibiting ADH release when this route of administration is used. ${ }^{817}$ Moreover, we cannot exclude the possibility of carbamazepine having a dual site of action, at both a renal and hypothalamic level, as recently proposed. ${ }^{18}$ In conclusion, our data indicate that patients treated with therapeutic doses of carbamazepine and phenytoin in combination show significantly less impairment of water clearance than patients on carbamazepine levels during phenytoin therapy. As phenobarbitone has a similar effect on serum carbamazepine levels ${ }^{910}$ it is likely to influence diuretic response in a similar way. Since the reduction in carbamazepine levels is quite marked, the risk of developing water intoxication is likely to be substantially less in patients on combination therapy than in patients receiving carbamazepine alone and clinical evidence supports this conclusion. ${ }^{2}$ The risk of water intoxication with carbamazepine as sole drug treatment may be particularly high if adjustments in dosage are made without the assistance of drug levels monitoring. The prescribed dose of carbamazepine has little or no predictive value in assessing the degree of antidiuretic effect, whereas the serum concentration provides a good indication. We suggest, therefore, that serum levels should be monitored routinely when carbamazepine is used alone and that patients stabilised on combination therapy with carbamazepine and phenytoin or other enzyme-inducing drugs should be watched carefully when the latter agents are discontinued or their dosage is reduced.

We thank the Medical Research Council for financial support, and Dr Jolyon Oxley, Senior Physician at the National Hospitals Chalfont Centre for Epilepsy, for allowing us to study patients under his care.

\section{References}

1 Henry DA, Lawson DH, Reavey P, Renfrew S. Hyponatraemia during carbamazepine treatment. Brit Med J 1977; 1:83-4.

2 Perucca E, Garratt A, Hebdige S, Richens A. Water intoxication in epileptic patients receiving carbamazepine. J Neurol Neursurg Psychiatry 1978; 41:713-8.

3 Ashton MG, Ball SG, Thomas TH, Lee MR. Water intoxication associated with carbamazepine treatment. Brit Med J 1977; 1:1134-5.

4 Smith NJ, Espir MLE, Baylis PH. Raised plasma arginine vasopressin concentration in carbamazepine-induced water intoxication. Brit Med J 1977; 2:804.

5 Stephens WP, Espir MLE, Tattersall RB, et al. Water intoxication due to carbamazepine. Brit Med J 1977; 1:754-5.

6 Sordillo P, Sagransky DM, Mercado R, Michelis MF. Carbamazepine-induced syndrome of inappropriate antidiuretic hormone secretion. Reversal of concomitant phenytoin therapy. Arch Intern Med 1978; 138:299-301.

7 Fichman MP, Kleeman CR, Bethune JE. Inhibition of antidiuretic hormone secretion by diphenylhydantoin. Arch Neurol 1970; 22:45-53.

8 Tanay A, Yust I, Peresenceschi G, Abramov AL, Aviram A. Long-term treatment of the syndrome of inappropriate antidiuretic hormone secretion with phenytoin. Arch Intern Med 1979; 90:50-2.

9 Christiansen J, Dam M. Influence of phenobarbital and diphenylhydantoin on plasma carbamazepine levels in patients with epilepsy. Acta Neurol Scand 1973; 49:543-6.

10 Cereghino JJ, Brock JT, Van Meter JC, Penry JK, Smith LD, White BG. The efficacy of carbamazepine combinations in epilepsy. Clin Pharmacol Ther 1975; 18:733-41.

11 Bertilsson L. Clinical pharmacokinetics of carbamazepine. Clin Pharmacok 1978; 3:128-43.

12 Dam M, Jensen A, Christiansen J. Plasma level and effect of carbamazepine in grand mal and psychomotor epilepsy. Acta Neurol Scand 1975; 60 (Suppl): 33-8.

13 Rane A, Höjer B, Wilson JT. Kinetics of carbamazepine and its 10,11-epoxide metabolite in children. Clin Pharmacol Ther 1976; 19: 276-83.

14 Westenberg HG, Van der Kleijn E, Oei TT, De Zeeuw RA. Kinetics of carbamazepine and carbamazepine-epoxide determined by use of plasma and saliva. Clin Pharmacol Ther 1978; 23:320-8.

15 Eichelbaum M, Köthe KD, Hoffmann F, Von 
Unruh GE. Kinetics and metabolism of carbamazepine during combined antiepileptic drug therapy. Clin Pharmacol Ther 1979; 26:366-71.

16 Fichman MP, Bethune JE, Kleeman CR. Inhibition of antidiuretic hormone by diphenylhydantoin. Clin Res 1967; 15:141.

17 Fichman MP, Bethune JE. The role of adreno- corticoids in the inappropriate antidiuretic hormone syndrome. Ann Intern Med 1968; 68: 806-20.

18 Stephens WP, Coe JL, Baylis PH. Plasma arginine vasopressin concentrations and antidiuretic action of carbamazepine. Brit Med J 1978; 1:1445-7. 